\title{
A Dinâmica Geográfica do Setor Supermercadista em Brasília (DF)
}

\author{
Geographic Dynamics of the Supermarket Sector in Brasília (DF)
}

\section{Juscelino Eudâmidas Bezerra ${ }^{1}$ \\ Marcelo Ramalho Agner ${ }^{2}$ iD}

\begin{abstract}
Palavras-chave:
Varejo alimentar

Estratégias territoriais

Distrito Federal

Resumo

A comercialização de alimentos nas cidades é cada vez mais influenciada pela presença das redes de supermercado, que são estabelecimentos de varejo de autosserviço com predominância de produtos alimentícios. O modelo de comercialização ágil, eficiente e de baixo custo foi o que mais se fortaleceu no contexto da urbanização da sociedade. No Brasil há uma demanda por estudos que possam contextualizar o panorama nacional da atuação do capital varejista nos demais centros urbanos localizados fora da região sudeste do país. O presente artigo tem como objetivo analisar a dinâmica geográfica do setor supermercadista em Brasília - DF por meio da compreensão da multiescalaridade da atuação das redes no território conforme sua origem de capital, as estratégias de localização e seus perfis de estabelecimento. A metodologia consistiu na produção e na sistematização de informações sobre o setor supermercadista por meio da evolução quantitativa e qualitativa dos estabelecimentos vinculados à Associação de Supermercados de Brasília (ASBRA). Conforme os resultados verificados na pesquisa, foi possível encontrar em Brasília as principais redes varejistas do mundo, o que demonstra a importância da capital federal como espaço de consumo na economia globalizada. A seletividade do uso do território pelas diferentes redes possibilitou a adoção de estratégias diferenciadas a depender do padrão de renda de cada região administrativa. A pesquisa contribuiu para evidenciar a heterogeneidade do setor e a conformação de estratégias comerciais adaptadas à realidade geográfica marcada por uma desigualdade socioespacial estrutural.
\end{abstract}

\section{Keywords:}

Food retail

Territorial strategies

Federal District

\begin{abstract}
The commercialization of food in cities is increasingly influenced by the presence of supermarket chains, which are self-service retail establishments with a predominance of food products. The agile, efficient, and low-cost marketing model was the one that was most strengthened in the context of the urbanization of society. In Brazil, there are few studies that seek to contextualize the performance of retail capital in other urban centers located outside the southeastern region of the country. This article aims to analyze the geographic dynamics of the supermarket sector in Brasília - DF through the understanding of the multi-scale performance of chains in the territory according to their capital origin, location strategies, and establishment profiles. The methodology consisted inof the production and systematization of information about the supermarket sector through the quantitative and qualitative evolution of establishments linked to the Associação de Supermercados de Brasília (ASBRA). As a result of this research, one can to locate the world's main retail chains in Brasilia, which demonstrates the importance of the country's capital as a consumption space in the globalized economy. The selective use of the territory by the different retail chains enabled the adoption of differentiated actions, dependent on the income pattern of each administrative region of the city. The research contributed to evidence the heterogeneity of the sector and the conformation of commercial strategies adapted to the geographic reality marked by structural socio-spatial inequality.
\end{abstract}




\section{INTRODUÇÃO}

A presença dos supermercados no comércio citadino é hoje uma realidade consolidada no Brasil, o que afeta diretamente a política de abastecimento, comercialização, distribuição e consumo de alimentos das famílias. Tudo isso faz parte de um fenômeno maior, representado pela difusão de novas práticas alimentares com repercussões diretas e indiretas no cotidiano de milhões de pessoas.

Desde a segunda metade do século XX, o Brasil passou a registrar um aumento do número de estabelecimentos comerciais na modalidade de autosserviço (supermercados). Tal situação ajuda a definir uma nova forma de transação comercial de alimentos, com o acesso direto às mercadorias por parte dos consumidores e a presença dos caixas para pagamento (check-outs).

O crescimento das grandes cidades e o fortalecimento do potencial de consumo do mercado interno foram fatores de propulsão para o investimento de redes nacionais e multinacionais no comércio varejista de alimentos no território brasileiro. A década de 1990 marca um ponto de inflexão na evolução do varejo, sendo decisiva para o estabelecimento de uma periodização baseada em ciclos estruturais. De acordo com Serrentino (2015), o varejo brasileiro pode ser analisado por meio de quatro ciclos agrupados em períodos, a saber: Préabertura/Real (até 1993), Pós-Real (1994-2003), boom de consumo (2004-2012) e maturidade e produtividade (iniciado em 2013).

Durante o primeiro ciclo, o setor do varejo seguia o contexto de uma economia fechada com elevado grau de informalidade e baixo poder de compra, limitado pela inflação crônica. O ano de 1994 demarca um segundo ciclo para o setor no Brasil com a abertura comercial e o lançamento do Plano Real, cuja nova moeda significou o controle da inflação, dado esse que limitou por muito tempo a expansão do varejo. Com isso, mediante o controle da inflação, houve um aumento de renda por meio do fim do imposto inflacionário; mudança na escala do mercado; estímulos ao processo de internacionalização do varejo e desenvolvimento do mercado de crédito. (SERRENTINO, 2015).

Nos primeiros anos da década de 2000, o setor viveu seu terceiro ciclo, que foi caracterizado pelo boom de consumo diante do cenário de fortes transformações econômicas e sociais. O foco foi a expansão por meio de abertura orgânica de novos estabelecimentos, criação de novos formatos, diversificação de negócios, entrada em novos mercados, movimentos de fusões e aquisições e capitalização de empresas. Destaca-se, ainda, a ampliação do grau de internacionalização, a entrada de fundos de private equity e o aumento da formalidade e da disseminação de tecnologia (SERRENTINO, 2015).

Segundo Serrentino (2015), o ano de 2013 demarca o quarto e último ciclo, marcado pela maturidade e pela produtividade. Os indícios de uma desaceleração econômica com níveis de crescimento negativo do PIB e a retração do consumo exigiram do setor do varejo investimentos na produtividade e com maior rigor na análise dos investimentos, aportes em infraestrutura e aprimoramentos nas operações dos estabelecimentos.

O quadro mais atual registrado pela Associação Brasileira de Supermercados ABRAS (REVISTA SUPERHIPER, 2019) indica que o setor do varejo de autosserviço, não obstante os momentos de crise, continuou a registrar crescimento no número de estabelecimentos. Assim, no ano de 2018, foram contabilizados, no país, 89.673 estabelecimentos de autosserviço espalhados em todas as regiões, cujo faturamento alcançou a cifra de $\mathrm{R} \$ 355,7$ bilhões, o que significou $5 \%$ do PIB nacional.

Dada a relevância do varejo de autosserviço para compreender a dinâmica urbana do consumo, o tema supermercados tornou-se um objeto de pesquisa de diversas áreas do conhecimento. $\mathrm{O}$ enfoque analítico da Geografia nos permite, por exemplo, examiná-los como estabelecimentos comerciais que exibem uma complexa rede geográfica com interações multiescalares e que demonstram uma atuação predominantemente urbana, muito embora com desdobramentos na relação campo e cidade, além de serem capazes de mobilizar um conjunto de setores, tais como a agricultura, a indústria, o transporte, a logística, a distribuição e o comércio (PINTAUDI, 1981; SILVA, 2003; CLEPS, 2005). Dito de outra forma, os supermercados estabelecem na contemporaneidade um verdadeiro exercício de gestão territorial que passa a ser uma condição sine qua non para sua existência na economia de fluxos, característica da globalização. Outrossim, representam a forma mais didática para compreender o elo entre produção e consumo materializado no gesto aparentemente simplório de pegar um produto na prateleira.

Mediante os estudos mais recentes sobre o varejo alimentar, novos temas passam a ser explorados pari passu às transformações do setor. Dentre as principais investigações, destacam-se aquelas que se voltaram ao entendimento da atuação territorial das empresas supermercadistas e seu processo de 
internacionalização (WRIGLEY et al, 2005; COE; WRIGLEY, 2018; COE, 2004; REARDON; BERDEGUE, 2002; HUMPHREY, 2007), do surgimento de novas tipologias de comércio e estratégias de localização e de concorrência (FARINA; NUNES; MONTEIRO, 2005; FERREIRA, 2013; MINADEOS; CARMARGOS, 2009), as práticas culturais de consumo (OOSTERVEER; GUIVANT; SPPARGAREN, 2010) e o papel dos supermercados na governança do setor agroalimentar (LAWRENCE; BURCH, 2007; OOESTERVEER; SONNENFELD, 2012; BEZERRA, 2012).

No Brasil há uma demanda por estudos que possam contextualizar o panorama nacional $\mathrm{da}$ atuação do capital varejista. A cidade de São Paulo e sua região metropolitana historicamente foram o recorte espacial privilegiado dessas pesquisas. Verifica-se, portanto, ainda, uma lacuna nas análises que perscrutam as características e as peculiaridades do processo de "supermercadização" no contexto de uma urbanização difusa.

O presente artigo tem como objetivo analisar a dinâmica geográfica do setor supermercadista em Brasília, considerada na totalidade das 33 regiões administrativas do Distrito Federal, por meio da compreensão da multiescalaridade de atuação das redes no território conforme sua origem de capital e o exame das estratégias de localização das redes e seus diversos perfis de estabelecimento.

A escolha do conjunto urbano de Brasília envolve o fato de que a cidade, equiparada a município, é a terceira mais populosa do país, logo após São Paulo e Rio de Janeiro. Brasília superou os três milhões de habitantes na estimativa populacional organizada pelo IBGE em 2018. Quando incluídos os municípios que compõem sua região metropolitana, delimitados pela Companhia de Planejamento do Distrito Federal (CODEPLAN, 2020), a população passa de quatro milhões.

No quesito renda e potencial de consumo, Brasília apresenta o maior índice de renda domiciliar per capita do país e o terceiro mercado em potencial de consumo (IPC MAPS,2020), ou seja, trata-se de uma localidade de demasiada importância na rede urbana brasileira.

Para a consecução da pesquisa a metodologia consistiu na produção e na sistematização de informações primárias através da visita aos estabelecimentos comerciais vinculados à Associação de Supermercados de Brasília (ASBRA) e dados secundários de órgãos públicos, documentos e publicações setoriais. Das 38 empresas associadas à ASBRA, foram contabilizados 193 estabelecimentos que serviram como o universo da pesquisa para posterior conferência e triagem, resultando num total de 175 estabelecimentos efetivamente visitados nos trabalhos de campo realizados in loco.

O artigo está dividido em duas seções, além da presente introdução e das considerações finais. A primeira dedica-se ao desenvolvimento geográfico do setor supermercadista em Brasília, ressaltando a evolução do número de estabelecimentos comerciais, sua atuação territorial, a presença das redes na cidade e a participação do capital local, nacional e internacional. A segunda seção busca analisar a estratégia do varejo multiformato como a mais utilizada pelas redes supermercadistas para sua expansão no contexto urbano na cidade a partir da criação de supermercados de vizinhança, supermercados convencionais, hipermercados e, mais recentemente, a difusão dos atacarejos.

\section{$O$ setor supermercadista em Brasilia: evolução e caracterização}

A década de 1950, período em que a cidade de Brasília começa a ser construída, marca o momento em que os primeiros supermercados começam a surgir e a se consolidar como um canal importante de comercialização de alimentos nas principais cidades brasileiras, com destaque para a capital paulista (FERREIRA, 2013).

A análise do setor varejista alimentício em Brasília traz desafios particulares por ser esta uma cidade planejada construída do zero e que já surge com demandas autoinduzidas. No ano de sua inauguração, em 1960, o Plano Piloto e os primeiros núcleos urbanos somavam, à época, mais de 140 mil habitantes (PAVIANI, 2007).

Os espaços de comercialização apresentavam uma localização pré-determinada no plano urbanístico de Lúcio Costa e eram situados em sua maioria no eixo comercial delimitado pela Avenida W3 nas porções Sul e Norte, bem como as áreas comerciais dispostas nas entrequadras residenciais. Com o término da construção da cidade e a vinda dos primeiros moradores das superquadras que foram transferidos da antiga capital, a constituição das "cidades satélites" e o aumento do fluxo migratório, a demanda por acesso regular a mercadorias e alimentação aumenta, forçando o governo a intervir.

O varejo de autosserviço em Brasília foi, a princípio, uma atividade de responsabilidade do Estado com a criação da companhia estatal Sociedade de Abastecimento de Brasília (SAB), fundada no ano de 1962. A SAB foi idealizada com o objetivo de suprir a demanda urbana de comercialização de alimentos no período em que 
as redes privadas inexistiam na capital federal, além de cumprir o papel de estimular a produção local de alimentos. A estatal chegou a ter sete estabelecimentos nas regiões administrativas (RA'S) do Plano Piloto, do Lago Sul, do Lago Norte e do Gama.

Ainda nas décadas de 1960 e 1970, outras redes de supermercado passaram a atuar em Brasília além da companhia estatal SAB, tais como os supermercados Casas da Banha, Supermercado Slaviero, Supermercado Planalto, Rede Somar, Minibox e Jumbo (Grupo Pão de Açúcar). Este último inaugurou o primeiro Hipermercado de Brasília, em 1971, no recém-inaugurado shopping Conjunto Nacional - o segundo shopping construído no Brasil -, localizado no coração da cidade, ao lado da rodoviária do Plano Piloto.

A chegada de redes privadas no setor do varejo contribuiu para a perda de competitividade da SAB, cujas atividades foram encerradas no final da década de 1980. Desde então, o varejo alimentício de Brasília passou a ser controlado, de fato, por empresas de redes locais, nacionais e internacionais, juntamente com a permanência dos centros de abastecimento, feiras e mercados públicos.

A dinâmica do setor supermercadista ao longo das últimas seis décadas demonstra que Brasília, assim como o Brasil, vivenciou na década de 1990 um crescimento vertiginoso do número de supermercados diante da abertura comercial, do maior controle da inflação e da criação de uma nova moeda (Real). Já no início do século XXI, o número de novos estabelecimentos mostrou-se ainda mais expressivo, o que ajuda a compreender a consolidação do poder de compra em função da estabilidade econômica, fator imprescindível para as empresas supermercadistas.

Mediante dados coletados junto aos estabelecimentos informantes (122) chegou-se ao número de estabelecimentos por década (Figura 1). Note-se que a informação corresponde aos dados que foram obtidos do campo, ou seja, não corresponde ao número real de todos os estabelecimentos que surgiram em Brasília.

\section{Figura 1 - Número de estabelecimentos comerciais inaugurados por década em Brasília (DF)}

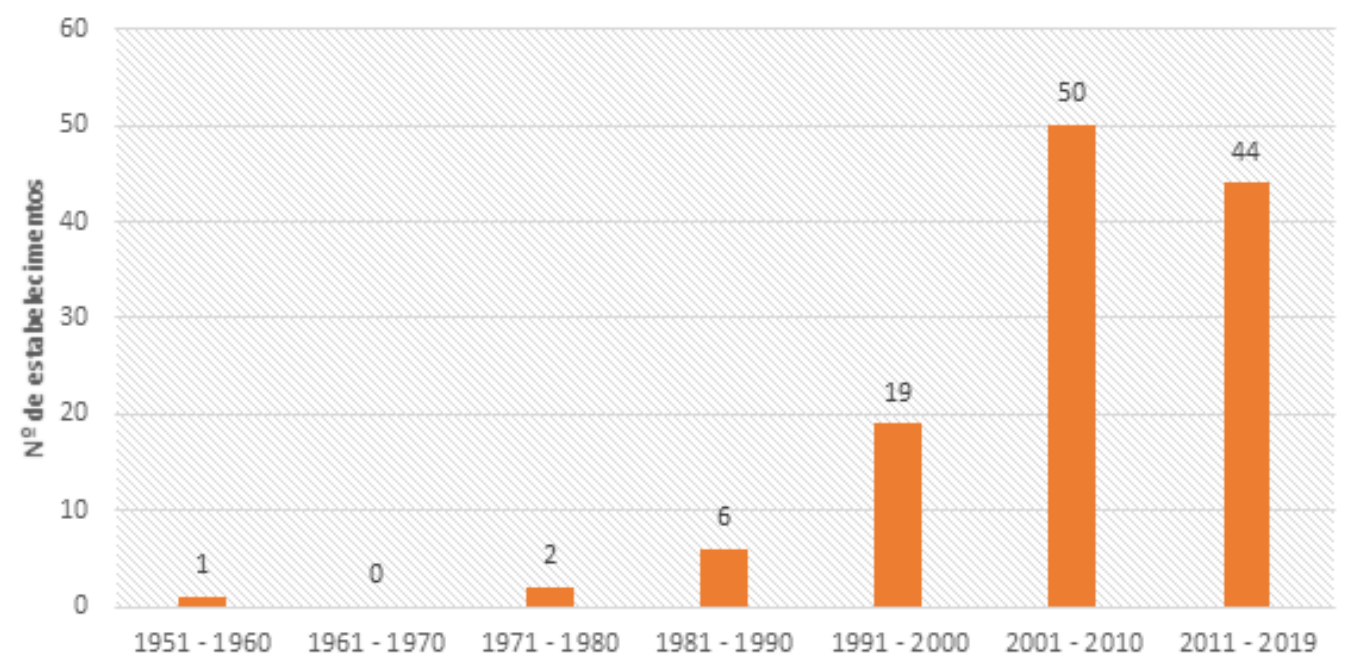

Fonte: Elaborado pelos autores com informações do trabalho de campo (2019)

Do ponto de vista da localização, foi possível observar o movimento de expansão de novos estabelecimentos para além da região do Plano Piloto - a primeira região administrativa a ser construída na capital -, em direção a regiões contíguas a partir da década de 1980. Assim, verificou-se que o grande aumento do número de estabelecimentos entre 1990 e 2000 ocorreu nas regiões administrativas de maior população e mais distantes dos extratos de alta renda, como Ceilândia, Sobradinho, Samambaia e Gama.

Com a evolução e a diversificação do setor supermercadista na capital federal, torna-se fundamental conhecer quais são as principais redes que atuam no território de Brasília de modo a compreender a conexão entre redes de capital local, nacional e internacional, cujas estratégias espaciais de atuação ocorrem em um contexto multiescalar. A escala geográfica de atuação do capital comercial é um dado relevante a se considerar visto que a multiescalridade é entendida como um recurso a ser utilizado nas estratégias territoriais, conferindo um maior poder de mercado. A escala está vinculada, conforme será demonstrado, à variedade de tipos de formato de estabelecimento escolhidos para cada território de atuação. 
Devido à inexequibilidade de averiguar o universo de todos os estabelecimentos de varejo de autosserviço em Brasília em todas as suas 33 regiões administrativas (RA's), foi preciso adotar uma estratégia que pudesse representar o setor supermercadista. Para tal, optou-se por analisar apenas as redes de supermercados que integram a Associação dos Supermercados de Brasília (ASBRA), por meio da sistematização de um banco de dados primários obtidos via realização de trabalhos de campo.

Das 38 empresas associadas à ASBRA, foram contabilizados 193 estabelecimentos dentro dos limites do Distrito Federal. A partir de investigações conduzidas no contexto do projeto de pesquisa financiado pela Fundação de Apoio à Pesquisa do Distrito Federal (FAPDF), intitulado "As redes de supermercado em Brasília: dinâmicas territoriais e estratégias de governança do setor agroalimentar", no período de 2016 a 2019, foram visitados 175 estabelecimentos, alcançando, portanto, mais de $90 \%$ do universo de estabelecimentos vinculados à ASBRA.

$\mathrm{O}$ primeiro fator a ser observado consiste na atuação territorial das redes, ou seja, em qual escala elas conseguem articular suas ações comerciais. A classificação desse fator foi elaborada da seguinte forma:

- As empresas que possuem apenas estabelecimento em Brasília são consideradas estabelecimentos locais;

- As empresas que possuem mais de um estabelecimento com atuação delimitada em Brasília são consideradas redes locais;

- As redes que possuem estabelecimentos em Brasília e em outra unidade federativa da região Centro-Oeste são redes regionais;

- As redes que possuem estabelecimentos em mais de uma macrorregião são consideradas redes nacionais;

- As redes que possuem no Brasil e em outros países são redes multinacionais.

Dentre as 38 empresas filiadas à ASBRA, foi identificado que 79\% (30) são estabelecimentos e redes locais; $11 \%$ (4), multinacionais; e $5 \%$, respectivamente, para o capital regional (2) e o nacional (2). Com relação à distribuição espacial dos supermercados em Brasília, constatou-se que as RA's com maior quantidade de estabelecimentos, na devida ordem, são: Plano Piloto (37), Taguatinga (22), Ceilândia (20), Águas Claras (15), Samambaia (13) e Guará (11).

Apesar de observar que a porcentagem de empresas locais é imensamente superior ao segmento de capital multinacional, a dinâmica geográfica evidencia uma participação qualitativamente diferente das redes no território de Brasília.

As principais empresas multinacionais representam aquelas que lideram o ranking ABRAS (REVISTA SUPERHIPER, 2019) e atuam nas cinco regiões brasileiras, como é o caso das francesas Carrefour e GPA (pertencente ao grupo Casino), a estadunidense Walmart e a holandesa Makro que, em fevereiro de 2020, foi vendida ao grupo francês Carrefour, mas durante a realização da pesquisa ainda pertencia ao seu grupo de origem.

O Carrefour atua em Brasília com várias modalidades de loja, sendo as mais destacadas as bandeiras Carrefour Bairro, Hipermercados Carrefour e Atacadão. O GPA, por sua vez, possui a bandeira Pão de Açúcar para lojas de bairro, o Extra para hipermercados e o Assaí para atacarejos. O Walmart (atual Grupo BIG) possui as bandeiras de nome próprio e a franquia do Sam's Club, enquanto o Makro utiliza a bandeira de nome próprio para atacarejo.

O segmento local (estabelecimentos e redes) possui uma grande quantidade de empresas e número de estabelecimentos comerciais; porém, sua atuação no território é muito restrita, sem operar concomitantemente nas distintas regiões administrativas. A exceção a esse quadro mais geral são aquelas redes que conseguiram maior grau de capilaridade territorial, tais como a rede Big Box, com 25 estabelecimentos e diversidade de formatos; Supercei, com 15 estabelecimentos em várias RA's; e Dona de Casa e Superbom, com 12 estabelecimentos cada.

Os segmentos nacional e regional apresentam pequena inserção em Brasília, o que reproduz a tendência mais geral que ocorre no país. Algumas redes nacionais, como o Grupo Pereira, detentor da bandeira Comper, e o Oba Hortifruti possuem recursos e estabelecimentos com localizações privilegiadas nas áreas de maior renda. O capital regional se confunde com a dinâmica da Área Metropolitana de Brasília (AMB), uma vez que são redes cuja influência em municípios goianos que fazem parte da AMB e em RA's próximas é bastante forte. Como exemplo dessa categoria, vale citar o caso das redes Tatico e Dia a Dia.

A evolução da questão demográfica no Distrito Federal aponta que a RA I - Brasília concentra o maior número de estabelecimentos, com 37 estabelecimentos, seguido de Taguatinga e Ceilândia, com 20 e 22 estabelecimentos, respectivamente. Acerca disso, é preciso pontuar que as regiões de maior contingente populacional não necessariamente concentram o maior número de estabelecimentos. Regiões administrativas de população elevada que 
contam com mais de 100 mil habitantes conforme as Projeções Populacionais para as Regiões Administrativas do Distrito Federal 2010-2020 (2018) como Planaltina, Recanto das Emas, Sobradinho II e Santa Maria e Gama não ultrapassam o número de sete estabelecimentos.

$\mathrm{O}$ contraste entre o contingente populacional e a concentração de estabelecimentos exige perscrutar uma relação mais complexa que permita analisar a dinâmica territorial do setor de supermercados no Distrito Federal. A partir disso foi escolhido o critério renda domiciliar como um fator determinante para examinar o perfil das regiões administrativas e o seu determinado grau de atuação no setor supermercadista.

A classificação das regiões administrativas por renda domiciliar média mensal feita pela PDAD (2018) divide as regiões em quatro grandes grupos, sendo eles: Grupo I - Alta renda: média domiciliar de RS 15.622; Grupo II - Média - Alta renda: média domiciliar de R\$ 7.266 ; Grupo III - Média - Baixa renda: média domiciliar de R\$ 3.101; Grupo IV - Baixa renda: média domiciliar de $\mathrm{R} \$ 2.472$.

A partir da estratégia de localização das redes supermercadistas (Figura 2), percebe-se como as redes varejistas usam o território de acordo com suas características sociais e econômicas em um contexto de imensa discrepância de renda domiciliar. Assim, a composição das regiões administrativas revela que em Brasília coexistem classes de renda com cerca de $R \$ 12.000$ reais de diferença entre si, como é o caso da diferença entre regiões do grupo de menor renda domiciliar, como o Setor Complementar de Indústria e Abastecimento (SCIA) - Estrutural e o grupo de maior renda domiciliar, como o Lago Sul.

Figura 2 - Localização dos supermercados, origem de capital e renda domiciliar em Brasília (DF)

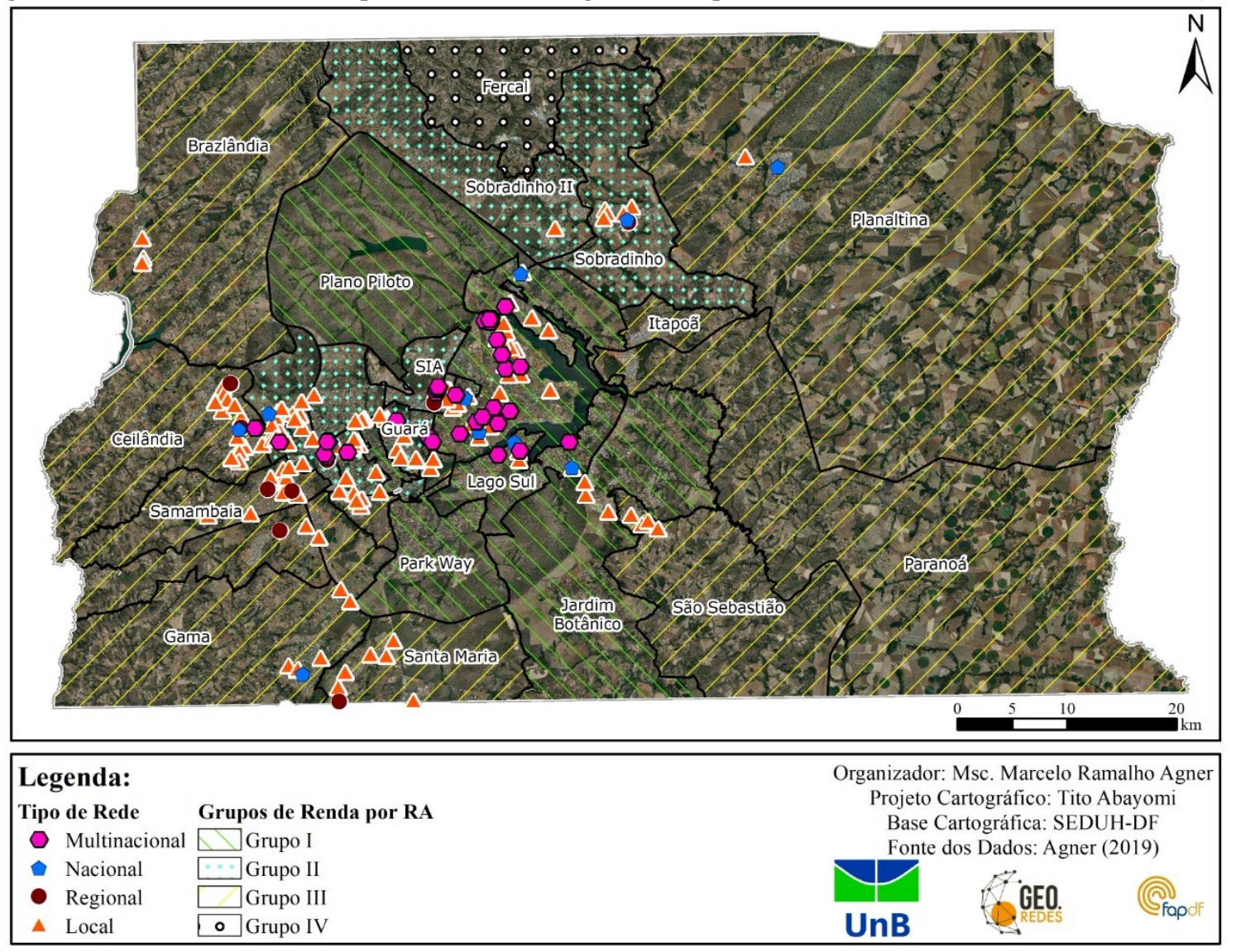

Fonte: os autores (2020).

Dentro dos próprios grupos também temos uma diversidade de situações, como é o caso do grupo de média - alta renda. Regiões como Águas Claras e Vicente Pires possuem aproximadamente $\mathrm{R} \$ 8.500$ de renda domiciliar mensal, enquanto as duas menores do grupo, Sobradinho e Núcleo Bandeirante, apresentam cerca de $R \$ 5.300$. No grupo de média - baixa renda também identificamos essa diferença, que reside na casa de $R \$ 2.300$ reais de diferença entre a maior e a menor do grupo.

Essa divisão entre grupos foi utilizada para ilustrar o potencial de consumo e a desigualdade socioespacial. Assim, apesar da média de renda 
ser muito maior do que a renda média do país, Brasília apresenta uma das maiores desigualdades de renda de acordo com o índice de Gini, alcançando 0,58 segundo a PDAD (2018).

Mediante a análise da localização e dos aspectos socioeconômicos, é possível verificar que há uma maior densidade de estabelecimentos nas regiões administrativas de maior renda familiar disponível e número elevado de população. Para além da relação entre fluxos urbanos e maior presença do comércio, é possível identificar que a participação das redes multinacionais está fortemente atrelada à concentração territorial de renda em Brasília.

Os estabelecimentos das redes multinacionais foram, por um lado, encontrados em somente nove das trinta e três regiões administrativas do Distrito Federal, sendo este grupo composto basicamente pela maior disponibilidade de poder de compra na cidade. Por outro lado, nas regiões de menor renda, observamos justamente o inverso, ou seja, identifica-se não somente a ausência de redes multinacionais, mas ainda também a menor densidade do número de estabelecimentos e a presença massiva de empresas locais.

Para que se possa melhor entender a expansão das redes de supermercado, é necessário averiguar a adoção do varejo de multiformato, pois esta é a estratégia principal na tentativa de adequação ao perfil dos consumidores nos distintos contextos urbanos.

\section{A configuração do varejo de multiformato: a diversificação como estratégia}

Um aspecto que diferencia a dinâmica das diferentes redes que atuam no setor do varejo na cidade diz respeito ao formato ou modelo de loja, isto é, como ela organiza sua cadeia de operações a partir do tipo de estabelecimento. Existem, então, inúmeras propostas de definições sobre os diferentes tipos de formato, em que os mais disseminados e com maior presença são os supermercados de vizinhança, os supermercados convencionais, os hipermercados e os atacarejos.

Os supermercados de vizinhança são definidos, conforme Borges (2001), pela localização em bairros residenciais. As dimensões variam, podendo chegar a no máximo $700 \mathrm{~m}^{2}$, média de 7 checkouts e 4 mil itens organizados em cinco seções básicas focadas exclusivamente em produtos alimentícios: mercearia, açougue, FLV, frios/laticínios e bazar.

Os supermercados convencionais apresentam maior quantidade e mix de produtos. Possui área de venda entre 700 a $2.500 \mathrm{~m} 2$, média de 9.000 itens ofertados e cinco seções tradicionais (mercearia, carne, frutas e verduras, frios e laticínios, nãoalimentos), e, às vezes, padaria, com destaque para os produtos de higiene e decoração, enquanto os supermercados de vizinhança focam em produtos alimentícios e compras diárias e semanais (BORGES, 2001). Outra diferença importante concerne à localização dos supermercados convencionais em shoppings e avenidas centrais de comércio.

$\mathrm{O}$ formato dos hipermercados possui em geral uma dimensão média de $2.500 \mathrm{~m}^{2}$, chegando a $15.000 \quad \mathrm{~m}^{2} \quad$ (SILVA, 2014). Nesses estabelecimentos, além das seções encontradas nos supermercados, comercializam-se também eletroeletrônicos, itens de livrarias, móveis e produtos para carros. O sortimento do mix é consideravelmente maior que os supermercados convencionais, utilizando um número entre $40 \mathrm{a}$ 70 checkouts e outros serviços integrados, tais como praças de alimentação, farmácias etc.

O atacarejo, cujo nome técnico do formato é atacado de autosserviço misto (cash and carry) caracteriza-se pela fusão do atacado (atividades envolvidas de produtos para revenda ou indústria) com o modelo do autosserviço de varejo. Baptista et al $(2012$, p. 6) analisa que "as lojas de atacarejo são, em média, $25 \%$ menores que os hipermercados. A área de vendas das lojas de vizinhança é $46 \%$ a dos supermercados". O formato atacarejo é o grande destaque do setor varejista no Brasil com número expressivos em termos de faturamento e crescimento no número de estabelecimenos comerciais. Segundo informações da ABRAS (REVISTA SUPERHIPER, 2019) o formato atacarejo foi responsável por $R \$ 37,6$ bilhões em vendas no ano de 2018.

A partir da caracterização dos diferentes formatos de loja, procedeu-se à classificação dos estabelecimentos verificados na pesquisa e sua localização em Brasília (Figura 3). Dos 191 estabelecimentos cuja localidade foi identificada, 96 eram supermercados de vizinahnça; 56, supermercados convencionais; 28, atacarejos; e 11, hipermercados. 
Figura 3 - Estabelecimentos segundo formato
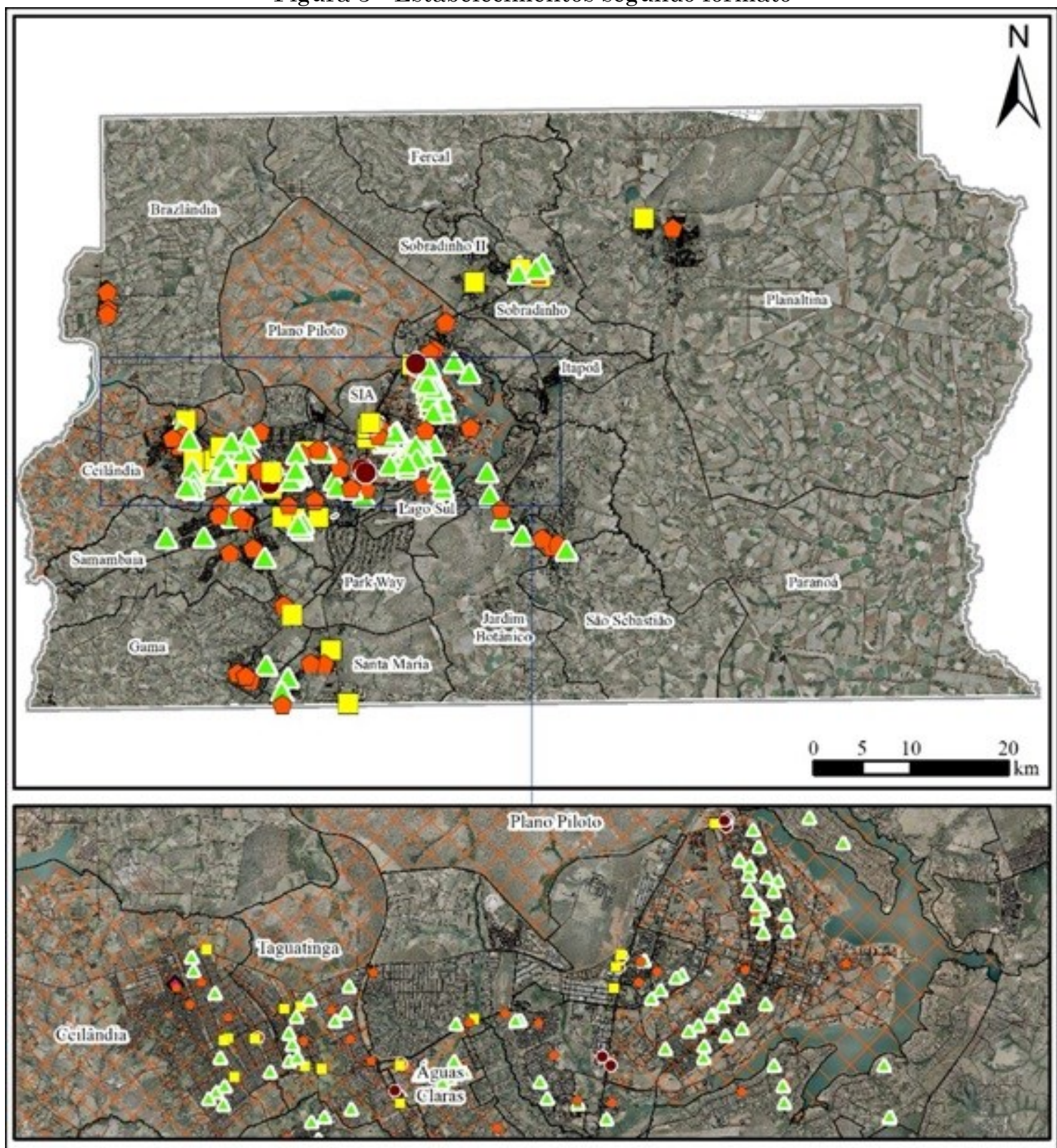

\section{Legenda:}

$\square$ Atacarejo

- Hipermercado

- Supermercado

A. Vizinhança

$\diamond$ Sem Classificação
Organizador: Msc. Marcelo Ramalho Agner Projeto Cartográfico: Tito Abayomi Base Cartográfica: SEDUH-DF Fonte dos Dados: Agner (2019)

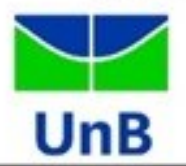

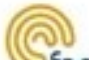

fapd

Fonte: os autores (2020).

O número de supermercados de vizinhança é quase o dobro do segundo maior formato supermercados convencionais - tendo em vista a maior facilidade com que esse formato se insere no tecido urbano por ser de menor proporção em termos de área e ter menor custo de aluguel, um mix de produtos diminuto e uma logística menos complexa. Esse fato, portanto, favorece a participação de pequenas empresas locais.
O número elevado de atacarejos, superior ao de hipermercados, ajuda a confirmar a tendência recente do setor do varejo de uma maior participação dos atacarejos como formato preferencial para os investimentos no setor, com Brasília acompanhando o que vem acontecendo nas demais cidades do país.

No entanto, a escalada dos atacarejos somente pode ser compreendida à luz do advento 
da crise econômica, visto que o crescimento do desemprego rebate diretamente na retração do consumo familiar, com impactos diretos nos gastos dos brasileiros. Assim, a procura pelos atacarejos, que ocorre tanto na classe média como nas classes de menor poder aquisitivo, reflete a necessidade de diminuição do peso do gasto com alimento no orçamento familiar.

O barateamento dos produtos por meio do ganho pela venda em grandes quantidades e o formato enxuto de operação fizeram com que os consumidores enxergassem nos atacarejos uma possibilidade diante da crise. De acordo com a Revista Super Hiper (2017) o atacarejo foi o único formato a não apresentar retração em suas vendas no período de 2010 a 2017.

O setor do capital multinacional foi o que mais rapidamente se adaptou à tendência de crescimento dos atacarejos. A rede Carrefour investiu prioritariamente na bandeira Atacadão, adquirindo, inclusive, 30 estabelecimentos da pioneira rede holandesa Makro. Faz-se, também, relevante ressaltar que a bandeira Atacadão é a única no país a estar presente em todos os estados e no Distrito Federal, sendo, portanto, a loja com maior capilaridade territorial existente no varejo alimentício. O GPA, por sua vez, busca expandir o Assaí, além de transformar alguns estabelecimentos de hipermercado da bandeira Extra, conforme aponta Koike (2019). Após a venda de suas operações do Walmart Brasil, os novos controladores do grupo Advent, por sua vez, optaram por concentrar investimentos nos estabelecimentos do clube atacadista Sam's Club (DESIDÉRIO, 2019).

Em Brasília, observou-se essa tendência no número de estabelecimento do tipo atacarejo, para além do fato de que algumas empresas como Dia a Dia, Super Adega, Atacadão e Sam's Club, que não atuavam em Brasília no começo da década passada, sequer existiam, o que mostra a expansão e a atual importância do formato para o setor supermercadista na cidade. A posse por parte de empresas multinacionais de diferentes bandeiras, responsáveis por vários formatos como supermercados de vizinhança, hipermercados e atacarejos, evidencia a capilaridade territorial dessas redes. Outras empresas, por seu turno, se atêm somente a um tipo de formato, seja por estratégia comercial, seja por limitações de ordem financeira.

Percebe-se, assim, que a estratégia mais difundida entre as grandes redes é a do varejo multiformato, no qual o atendimento aos consumidores acontece em estabelecimentos com perfis diferentes integrados à mesma rede. No Brasil, as redes Carrefour e Grupo Pão de
Açúcar/Casino são as que mais se enfrentam em todos os formatos.

\section{CONSIDERAÇÕES FINAIS}

Em Brasília, é possível encontrar as principais redes varejistas do mundo, o que demonstra a importância da capital federal como espaço de consumo na economia globalizada. Nesse sentido, a pesquisa contribuiu para evidenciar a heterogeneidade do setor e a conformação de novas estratégias comerciais adaptadas à realidade geográfica, marcada por uma desigualdade socioespacial estrutural.

Foi possível constatar a seletividade do uso do território pelas redes, em especial pelas de capital internacional. $\mathrm{O}$ poder das multinacionais se expressa não somente na quantidade de estabelecimentos existentes e em sua refinada estratégia de localização, mas sobretudo na sua capacidade de ofertar diferentes formatos de loja. As regiões com maior poder aquisitivo, especialmente a região do Plano Piloto, são as que registram a maior diversidade de formatos, tais como os supermercados de vizinhança, supermercados convencionais, hipermercados e, mais recentemente, a difusão dos atacarejos.

Outro fator que chamou atenção foi o crescimento do número de atacarejos como formato prioritário nos investimentos realizados pelas redes locais e multinacionais, conformando uma tendência nacional na criação de estabelecimentos com menor custo operacional, eficiência logística e uma política de preço final mais agressiva em consonância com o momento de crise econômica.

A pesquisa sobre os impactos socioespaciais do avanço do capital varejista contribui, portanto, de maneira decisiva para a reflexão sobre a importância do comércio de alimentos na cidade, sendo conveniente uma perspectiva crítica com relação ao poder do capital comercial a partir da adoção de variáveis tanto políticas quanto econômicas. A Geografia, desse modo, oferece análises preciosas ao direcionar seu foco de análise para as estratégias espaciais de controle do mercado a partir do contexto urbano, regional e intraurbano.

\section{FINANCIAMENTO}

Fundação de Apoio a Pesquisa do Distrito Federal - FAPDF. Edital de Demanda Espontânea 
REFERÊNCIAS

AZEVEDO FILHO, G. L. S. As grandes redes no setor supermercadista brasileiro e seus impactos na concorrência em Brasília. 2016. 99f. Monografia (Graduação em Geografia) - Instituto de Ciências Humanas, Universidade de Brasília, Brasília, 2016.

BAPTISTA, J. A. et al. Canais de distribuição Logístico Atacarejo: Um estudo de caso na empresa XYZ Dist. Com. Ind. Ltda. In: IX SIMPÓSIO DE EXCELÊNCIA EM GESTÃO E TECNOLOGIA, Rio de Janeiro, 2012, Anais,p.1-16.

BEZERRA, J. E. A fruticultura no Nordeste semiárido: internacionalização, conflitos territoriais e a precarização do trabalho. 2012. 376p. Tese (Doutorado em Geografia) Universidade Estadual Paulista, Presidente Prudente, 2012.

BORGES, A. R. Marketing de Varejo: as estratégias adotadas pelos supermercados de vizinhança para conquistar e fidelizar clientes. 2001. 155f. Dissertação (Mestrado em Engenharia da Produção) - Centro Tecnológico, Universidade Federal de Santa Catarina, Florianópolis, 2001.

CLEPS, G. D. G.. Estratégias de reprodução do capital e as novas espacialidades urbanas: o comércio de auto- serviço em Uberlândia - MG. Tese (Doutorado em Geografia) - Instituto de Geociências e Ciências Exatas, Universidade Estadual Paulista, Rio Claro, 2005.

CODEPLAN. Pesquisa Distrital por Amostra de Domicílios - PDAD 2018. Disponível em: http://www.codeplan.df.gov.br/wp-

content/uploads/2019/03/PDAD_DF-Grupo-deRenda-compactado.pdf/. Acesso em: 17 abr. 2019.

CODEPLAN. Projeções Populacionais para as Regiões Administrativas do Distrito Federal 2010-2020. Disponível em: http://www.codeplan.df.gov.br/wpcontent/uploads/2019/05/Sum\%C3\%A1rioExecutivo-Proje\%C3\%A7\%C3\%B5es-

Populacionais.pdf . Acesso em: 12 abr. 2020

COE, N.. M; WRIGLEY, Neil. Towards new economic geographies of retail globalization. In: CLARK, G. L., FELDMAN, M. P., GERTLER, M. S., WOJCIK, D. and KAISER, A. (eds.). The New Oxford Handbook of Economic Geography. Oxford: Oxford University Press, 2018.

https://doi.org/10.1093/oxfordhb/97801987556 09.013 .37
COE, N. M. M. The internationalisation/globalisation of retailing: towards an economic-geographical research agenda. Environment \& Planning A,v.36, n. 9, p. 1571-1594, 2004. https://doi.org/10.1068/a36241

DELLOITE. Global Powers of Retailing, 2019. Disponível em: https://www2.deloitte.com/br/pt.html. Acesso em: 10 out. 2019 .

DESIDÉRIO, M. Sem Walmart, Sam's Club vira pilar do Grupo Big e ganha novas lojas. Revista Exame, São Paulo, set. 2019. Disponível em:

https://exame.com/negocios/sem-walmartsams-club-sera-pilar-para-crescimento-dogrupo-big/. Acesso em: 12 set. 2019.

EXAME. Carrefour compra 30 lojas da rede Makro para acelerar atacadão. Revista Exame, São Paulo, fev. 2020. Disponível em: https://exame.com/negocios/carrefour-compra30-lojas-da-rede-makro-para-aceleraratacadao/ . Acesso em: 5 mar. 2020.

FARINA, E.; NUNES, R.; MONTEIRO, G. Supermarkets and Their Impacts on the Agrifood System of Brazil: The Competition among Retailers. Agribusiness, v. 21, n. 2, p. 133-47,

2005.

https://doi.org/10.1002/agr.20039

FERREIRA, P. R. A.. O processo de globalização do varejo de massa e as lutas competitivas: o caso do setor supermercadista no Brasil. 2013. $286 \mathrm{f}$. Dissertação (Mestrado em Administração) Instituto COPPEAD de Administração, Universidade Federal do Rio de Janeiro, Rio de Janeiro, 2013.

HUMPHREY, J. The supermarket revolution in developing countries: tidal wave or tough competitive struggle? Journal of Economic Geography, v.7, n.4, p. 433-450, 2007. https://doi.org/10.1093/jeg/lbm008

KOIKE, Beth. Assaí ganhará 20 novas lojas em 2019 e mais três no começo de 2020. Valor Econômico, São Paulo, out. 2019. Disponível em:

https://valor.globo.com/empresas/noticia/2019/ 10/31/assai-ganhara-11-novas-lojas-em-2019e-mais-tres-no-comeco-de-2020.ghtml. Acesso em: 05 nov. 2019.

Instituto Brasileiro de Geografia e Estatística (IBGE). Projeções da população. Rio de Janeiro: IBGE, 2018. Disponível em: https://www.ibge.gov.br/estatisticas/sociais/po pulacao/9109-projecao-da-

populacao.html?=\&t=resultados. Acesso em: 02 nov. 2019.

LAWRENCE, G.; BURCH, D. Understanding Supermarkets and Agri-food Supply chains. 
In: LAWRENCE, Geoffrey; BURCH, David. (Org.). Supermarkets and Agri-food Supply Chains: Transformations in the Production and Consumption of foods. London: Edward Elgar, 2007.

LAZZARINI, J. C. A definição do sortimentoprofundidade nos supermercados brasileiros: influência nas vendas e critérios utilizados. 2012. 255f. Dissertação (Mestrado em Administração) - Faculdade de Economia, Administração e Contabilidade, Universidade de São Paulo, São Paulo, 2012.

MARKETING, IPC. IPC Maps. São Paulo: IPC Marketing. $2012 . \quad$ v. 4. http://www.ipcbr.com/downpress/Release_IPC Maps_2020.pdf. Acesso em: 02 nov. 2020.

MINADEO, R.; CAMARGOS, M. A. Fusões e Aquisições no Varejo Alimentar: uma análise das estratégias de entrada e de crescimento do Carrefour e Wal-Mart no mercado brasileiro. Revista de Ciências da Administração, v. $11, \quad$ p. $\quad 102-135, \quad 2009$. https://doi.org/10.5007/21758077.2009v11n24p102

OOESTERVEER, P.; SONNENFELD, D. A. Food, Globalization and Sustainability. London/New York: Earthscan, 2012. https://doi.org/10.4324/9781849776790

OOSTERVEER, P.; GUIVANT, J. S.; SPPARGAREN, Gert. Alimentos verdes em supermercados globalizados: uma agenda teórico-metodológica. In: GUIVANT, Julia. S.; SPAARGAREN, Gert.; RIAL, Carmen. (Org.). Novas práticas alimentares no mercado global. Florianópolis: Editora da UFSC, 2010.

PAVIANI, A. Geografia urbana do Distrito Federal: evolução e tendências. Espaço \& Geografia, Brasília, v. 10, n.1, p. 1-22, 2007.

PINTAUDI, S. M. Os supermercados na grande São Paulo: contribuição ao estudo da transformação do comércio varejista de gêneros alimentícios nas grandes metrópoles. 1981. 105f. Dissertação (Mestrado em Geografia) - Faculdade de Filosofia, Letras e Ciências Humanas, Universidade de São Paulo, São Paulo, 1981.

REARDON, T.; BERDEGUÉ, J. A. The rapid rise of supermarkets in Latin America: challenges and opportunities for development.
Development Policy Review,v. 20, n. 4, p. 371-388, 2002. https://doi.org/10.1111/14677679.00178

REVISTA SUPERHIPER. São Paulo: ABRAS. Ranking ABRAS. Maio, 2019. Disponível em:https://www.abras.com.br/superhiper/edic oes-anteriores/.Acesso em: 10 Abril. 2019.

REVISTA SUPERHIPER. São Paulo: ABRAS. Os motores da economia voltam a funcionar. Dezembro, 2017. Disponível em: https://www.abras.com.br/superhiper/edicoesanteriores/. Acesso em: 10 set. 2019.

SERRENTINO, A. Varejo e Brasil: reflexões estratégicas. São Paulo: Varese, 2015.

SILVA, C. H. C. As grandes superfícies comerciais: os Hipermercados Carrefour no Brasil. Espaço e Tempo, São Paulo, n. 14, p. 89-106,

2003.

https://doi.org/10.11606/issn.2179-

0892.geousp.2003.123834

SILVA, C. H. C. Estudos sobre o comércio e o consumo na perspectiva da geografia urbana. Geosul, Florianópolis, v. 29, n. 58, p 149-178, jul./dez. 2014.

SILVA, I. V. I. A dinâmica das redes supermercadistas em Taguatinga e sua relação com o território. 2017. $78 f$. Monografia (Graduação em Geografia) Instituto de Ciências Humanas/Departamento de Geografia, Universidade de Brasília, Brasília, 2017.

WRIGLEY, N.; COE, N. M; CURRAH, A. Globalizing retail: conceptualizing the distribution-based transnational corporation (TNC). Progress in Human Geogrraphy, v. 29, n. 4, p. 437-457, 2005. https://doi.org/10.1191/0309132505ph559oa

\section{CONTRIBUIÇÃO DOS AUTORES}

Juscelino Eudâmidas Bezerra foi responsável pela concepção do estudo, aquisição de recursos financeiros, supervisão, desenho da metodologia, seleção dos dados, redação do texto. Marcelo Ramalho Agner coletou e analisou os dados, realizou trabalho de campo, organizou o material cartográfico e redigiu o texto. 